\title{
Effects of Region and Elevation on Adaptation of Leaf Functional Traits of an Invasive Plant Erigeron annuus in China
}

\author{
Yuanyuan Liu, Zhen Li, Lie Xu, Qiang Fu* and Yongjian Wang \\ College of Horticulture \& Forestry Sciences, Hubei Engineering Technology Research Center for Forestry Information, Huazhong \\ Agricultural University, Wuhan, 430070, China \\ *Corresponding Author: Qiang Fu. Email: fuqiang@mail.hzau.edu.cn \\ Received: 16 December 2020 Accepted: 16 April 2021
}

\begin{abstract}
A key scientific challenge relating to the threat of invasive plants on agriculture at the region level is to understand their adaptation and evolution in functional traits. Leaf functional traits, related to growth and resource utilization, might lead to adaptation of invasive plants to the geographical barriers (region or elevation). In the field experiment, we discussed the effects of region and elevation on leaf functional traits on invasive plant Erigeron annuus in farmland habitats in China. We compared leaf size, coefficient of variation (CV) of leaf traits, and fluctuating asymmetry (FA) of E. annuus from three regions (east $v s$. center $v s$. west) and two leaf types (vegetative $v s$. reproductive leaf), and from nine elevations (980-2100 $\mathrm{m}$ ) in the west region of China. Our results indicated region and leaf type influenced leaf functional traits, and leaf size was significantly higher and CV of leaf traits and FA in reproductive leaves were significantly lower in the east region than in the west and center regions. Elevation and leaf type affected leaf functional traits, and leaf size was significantly higher and CV of leaf traits in reproductive leaves were significantly lower in moderate elevation. E. annuus has higher leaf size and developmental stability (lower CV and FA) in the eastern region due to the longer adaptation period. Therefore, leaf functional traits play an important role in the adaptation of different longitudes and elevations. It can also facilitate the understanding of the invasiveness and adaptation of leaf traits of invasive plants in the agricultural ecosystem during their spread process in China.
\end{abstract}

\section{KEYWORDS}

Invasive alien plants (IAS); leaf traits; coefficient of variation; fluctuating asymmetry; developmental stability

\section{Introduction}

Distribution of many plants are not only determined by environment gradient but may also be influenced by physical dispersal barrier so as to prevent them from that spatial movement tending to broaden the region [1-3]. With the development of transportation, the dispersal to barriers have been breached, human beings help many species to expand their distributional range intentionally or unintentionally. Furthermore, exotic plants spread frequently under the influence of global climate change [4]. When plant species are introduced to a new suitable region, there will be a rapid increase in distribution and abundance because of a decrease in regulation by herbivores and other natural enemies $[5,6]$. Some other plants become invasive species via their own competition mechanism, such as allelopathy and functional traits [7-9]. The strong adaptability of exotic invasive species over native plants is often explained by their functional traits, such as faster 
growth rates, higher resource uptake, higher specific leaf areas, and leaf growth stability [4,9-11]. Exotic plant populations can use traits dominance to adapt to changed environments and defeat competitors in the new conditions of exotic communities [10-12]. The key for exotic species to settle is decided by synthesis of abiotic conditions and traits adaptation [13-15].

The reason why many alien plants spread rapidly is not only because their own competition stronger than native, but also owing to their resource availability [11,16-20]. In fact, at least $90 \%$ of alien plant species are confined to naturally and anthropogenically disturbed habitats including ruderal, urban, arable land, and riverine [21,22]. Only a minority of alien plant species appeared in the undisturbed mountain areas, because it is difficult for the dispersal of plant propagules to reach higher elevation [23,24]. According to intermediate disturbance hypothesis, invasive plants should be adapted to moderate elevation of mountain regions [25]. The lack of adapting to harsh environments of invasive plant populations is the main determinant to the declining abundance at higher altitudes [24,26]. Therefore, invasive plants can exist in resource-rich, disturbed habitats, the hinge on further spread is contingent depend upon plastic responses or genetic adaptation to new ecological environments [10-11,25].

A common genotype can produce different phenotypes in different surroundings. This fundamental property of organisms is defined as phenotypic plasticity [27]. Phenotypic plasticity is universal in nature, and often involves ecologically relevant behavioral, physiological, morphological and life-historical traits $[28,29]$. Consequently, plasticity alters numerous interactions between organisms and their abiotic and biotic circumstances [30]; it is also a strategy of environment adaptation [31]. The resources (temperature, nutrient, water and radiation etc.) are unevenly distributed across earth's surroundings for plants, which result in heterogeneity of habitats. When suffered from severe environment, plants need adaptive methods or strategies to survive, such as phenotypic plasticity. In other word, plants can fit various habitats through phenotypic plasticity, it is good for keeping the populations prosperity and stable [32,33]. Phenotypic plasticity exists widely in nature including ecology relevant of examining dynamic, anatomical/architectural, and cross-generational plasticity along with simpler growth traits [27,30,34]. Phenotypic plasticity is a major mode of adaptation in plants; it can influence their capacity of adaptations [35]. Functional traits related to phenotypic plasticity may also differ between exotic species and native species. Leaf traits and root-shoot ratio have been found to be positively related to relative growth rate (RGR). Meanwhile, coefficient of variation (CV) of leaf functional traits of plants, indicating plasticity of the traits may be the key drivers of mechanisms affecting growth [30-34]. Once the biotopes are disturbed, the plant species possibly disappears in the environment. Generally speaking strong plastic plant species do not need to adapt new diverse ecological niche by natural selection.

Developmental stability reflects the ability of individuals to experience stable development of their phenotype under a range of environmental conditions [36]. Individuals suffer from various interference pressures with the development of their phenotype, the high developmental stability one can adjust their law of development to the environmental conditions. During the reproductive growth of plants, the reproductive leaves and flowers consume a lot of nutrients as a metabolic pool, and there is a strong "sink-source" relationship with the vegetative leaves. As a result, there are certain differences in nutrient cycles and traits between the reproductive leaves and the vegetative leaves [37]. It will be reflected by their phenotype, such as a deviation of plants' fluctuating symmetry in their leaves. Fluctuating asymmetry (FA) can measure the influence of environmental pressures on developmental stability; it also reflects ability of the plants' adaptation [37-39]. CV of traits can show the variation of growth to environment, $\mathrm{CV}$ of the leaf traits and fluctuating asymmetry of leaf (FA) together can help them settle down easily in a strange biotope. A great deal of scientific research proved that FA has been suggested as a useful indicator of environmental stress; hence, the indicator rises by a gradual increase towards environmental stress. FA is relevant to elevation, region, competition, temperature, etc. [36,40-44]. When exotic plants just invade in new habitats, it had less time to adapt new environment, which mean that 
invasive plants might have high variation of FA. Thus, FA will be influenced by invading early or late, and it is a useful indicator in judging invasive plants' adaptation.

Erigeron annuus was allopatric initially and morphologically distinct species in most of their geographic distribution in Mexico and North America [45,46]. It was first brought to Shanghai in the early 19th century, then through above 50 years of stagnation, gradually spread from coastal to the inland. Moreover, E. annuus spread widely in the warm temperate to subtropical area of China at present, such as ruderal, urban, arable land, and riverine. We measured individual biomass, leaf traits (e.g., leaf length, leaf width, length/width of leaf and leaf area), coefficient of variation (CV) of the leaf traits and fluctuating asymmetry of leaf area and of leaf width (FAA and FAW) of three different regions (east, center and west) along same latitude, from coastal to the inland, in intermediate section of China. In addition, to address the effects of elevation (environmental changing, i.e., temperature, humidity), leaf traits, $\mathrm{CV}$ of the leaf traits and FA were quantified along 9 different elevations on the same horizon, from 980 to $2100 \mathrm{~m}$, in the west region in Chongqing $\left(29^{\circ} 03^{\prime}-29^{\circ} 50^{\prime} \mathrm{N}, 106^{\circ} 20^{\prime}-107^{\circ}\right.$ $14^{\prime} \mathrm{E}$ ). Besides, we also try to understand whether it is difference between vegetative leaves (leaves on the main stem at the beginning of the vegetative growth) and reproductive leaves (leaves on the branches of the inflorescence at the beginning of the reproduction period). If the elevation restriction is due to physiological constraints, then growth and reproductive performance of the annual plant should be limited at $1000 \mathrm{~m}$ due to high mortality and reduced growth and reproduction [47-49]. Therefore, we tested the two hypotheses: 1) region and leaf type influence leaf functional traits, and leaf size may be higher and CV of leaf traits and FA in reproductive leaves may be lower in the east region than in the west and center regions; 2) elevation and leaf type will affect leaf functional traits, and according to intermediate disturbance hypothesis, leaf size may be higher and $\mathrm{CV}$ of leaf traits and FA in reproductive leaves may be lower in moderate elevation.

\section{Materials and Methods}

\subsection{Study Sites}

This study was conducted in China where three regions were sampled (Tab. 1, Fig. 1): 1) Eastern region, (North and South part of Zhejiang Province), Zhejiang has a subtropical monsoon climate, with an average annual temperature of 16.4 or $17.5^{\circ} \mathrm{C}$ and an average annual rainfall of 1480 or $1607 \mathrm{~mm}$ in the north and south, respectively, aim species existed 1890s-1910s. 2) Central region (North and South of Hubei Province), Hubei has a subtropical monsoon climate, the average annual temperature is $16.4^{\circ} \mathrm{C}$, and the average annual precipitation is $1300 \mathrm{~mm}$, aim species existed 1930s-1940s. 3) Western region (North and South of Chongqing), Chongqing belongs to the subtropical monsoon humid climate, the annual average temperature is 11.3 or $14.6^{\circ} \mathrm{C}$, the annual average precipitation is relatively rich, in most areas of 1396 or $1612 \mathrm{~mm}$, aim species existed 1960s-1970s [50,51]. In the first investigation, we chose the sites with the similar elevations and environments in the above three regions. The first study area was in Ningbo and Taizhou $\left(28^{\circ} 51^{\prime}-30^{\circ} 332^{\prime} \mathrm{N}, 120^{\circ} 55^{\prime}-122^{\circ} 16^{\prime} \mathrm{E}\right)$, Mulan mountain and south lake $\left(29^{\circ} 58^{\prime}-31^{\circ} 22^{\prime} \mathrm{N}\right.$, $\left.113^{\circ} 41^{\prime}-115^{\circ} 05^{\prime} \mathrm{E}\right)$, Jinfo and Jinyun Mountain Nature Reserve $\left(29^{\circ} 03^{\prime}-29^{\circ} 50^{\prime} \mathrm{N}, 106^{\circ} 20^{\prime}-107^{\circ} 14^{\prime} \mathrm{E}\right)$. In the second investigation, 9 sites in different elevations $(980,1086,1270,1350,1480,1600,1800$, $1920,2100 \mathrm{~m}$ ) in western region were subjected, between the sites, the temperature dropped $0.6^{\circ} \mathrm{C}$ for every 100 meters increase in elevation. The elevation of Jinfo Mountain ranges between 340 and $2216 \mathrm{~m}$, the average annual temperature is $8.3^{\circ} \mathrm{C}$ and the mean annual precipitation is $1395.5 \mathrm{~mm}$ [52].

\subsection{Study Plant}

E. annuus (Asteraceae) occurs in eastern North America and is a winter annual species that varies from deciduous and riparian habitats [46]. The seeds of E. annuus germinate in August, seedlings overwinter as rosettes and plants bolt and flower the following summer. Some plants may reproduce as rosettes until the second or third summer instead of first year. It is triploid and apomictic. Seed production is high: a single plant may produce as many as 100,000 genetically identical tiny wind-dispersed seeds [45]. 
Table 1: Environmental features of plots of Erigeron annuus in different regions and directions of China

\begin{tabular}{llllllll}
\hline Region & Direction & $\begin{array}{l}\text { Slope } \\
\left({ }^{\circ}\right)\end{array}$ & Longitude & $\begin{array}{r}\text { Latitude } \\
\text { Average annual } \\
\text { temperature }\left({ }^{\circ} \mathrm{C}\right)\end{array}$ & $\begin{array}{l}\text { Average annual } \\
\text { rainfall }(\mathrm{mm})\end{array}$ & Habitats \\
\hline East & South & $0-1$ & $121^{\circ} 25^{\prime}$ & $28^{\circ} 39^{\prime}$ & 17.5 & 1607 & Farmlands \\
East & North & $0-2$ & $121^{\circ} 37^{\prime}$ & $29^{\circ} 51^{\prime}$ & 16.4 & 1480 & Farmlands \\
Center & South & $0-2$ & $114^{\circ} 21^{\prime}$ & $30^{\circ} 28^{\prime}$ & 16.5 & 1300 & Farmlands \\
Center & North & $0-2$ & $114^{\circ} 23^{\prime}$ & $31^{\circ} 05^{\prime}$ & 16.4 & 1300 & Farmlands \\
West & South & $2-5$ & $107^{\circ} 11^{\prime}$ & $29^{\circ} 10^{\prime}$ & 11.3 & 1396 & Farmlands \\
West & North & $2-3$ & $106^{\circ} 23^{\prime}$ & $29^{\circ} 50^{\prime}$ & 14.6 & 1612 & Farmlands \\
\hline
\end{tabular}

Note: http://data.cma.cn.

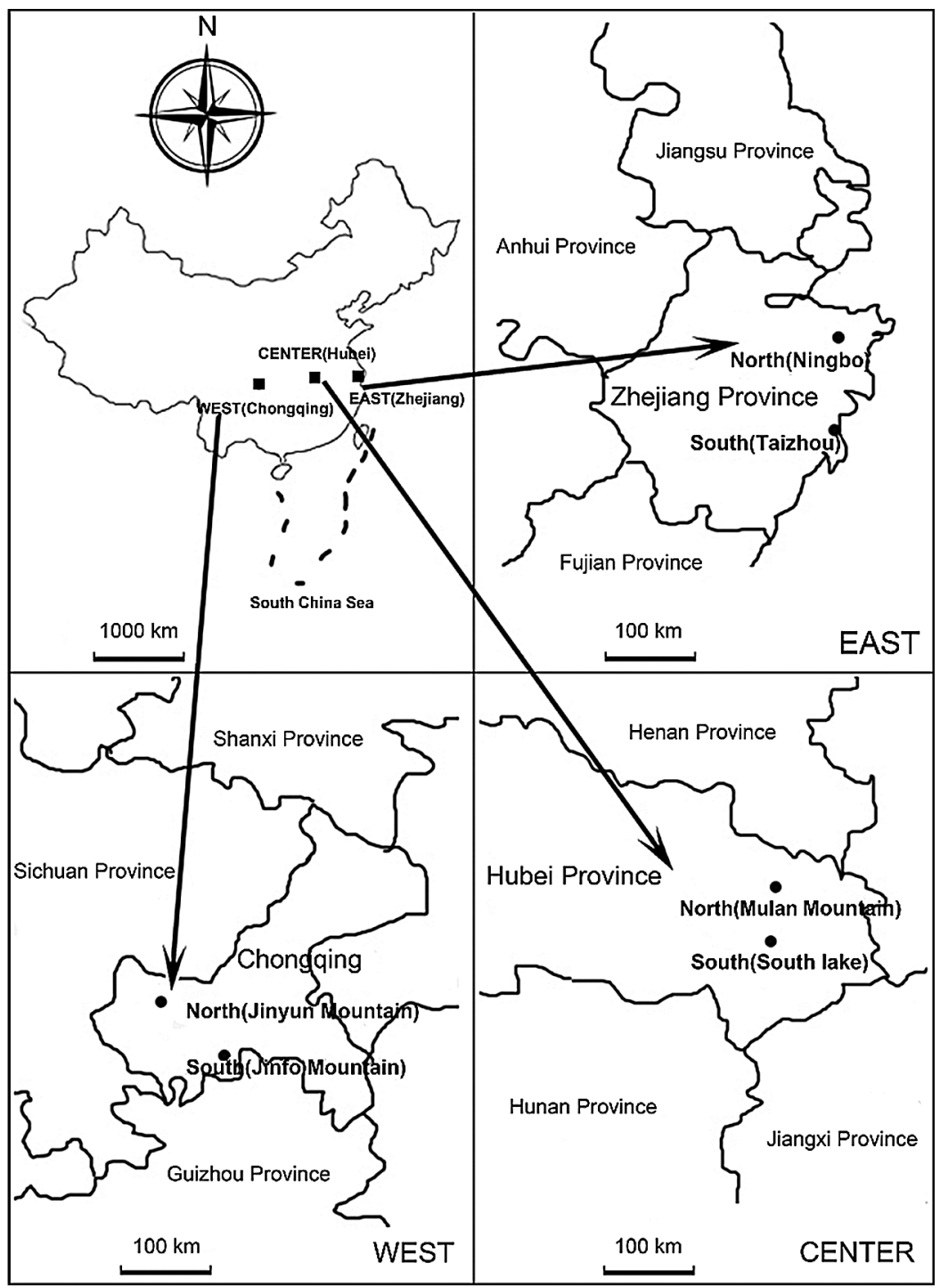

Figure 1: Plots of Erigeron annuus in different regions and directions of China. Three black solid squares represent sampled regions of east, center and west in China, respectively. Two black solid circles represent sampled directions of south and north in each region 


\subsection{Sample Collection and Measurement}

In the first study, surveys were conducted from July to August in 2011 and 2012. We chose 6 independent sites, eastern region (North and South part of Zhejiang Province), central region (North and South of Hubei Province) and western region (North and South of Chongqing), to determine the patterns of ramets, biomass and leaf morphology in E. annuus. In 2011, we selected 4 populations of E. annuus in each site during July and August. From each population, 10 mature and complete plants were sampled and separated to roots, stems, leaves and flowers and put them into envelopes respectively, then dried for biomass analysis. The dry weight of shoots was calculated by adding the dry weight of the stems, leaves and flowers. Root-to-shoot ratio (R/S ratio) is determined by shoot dry mass/root dry mass. We measured number of ramets per plant and R/S ratio to evaluate the population adaptation. In 2012 of July and August, we selected the same four populations in each site. From each population, ten complete vegetative leaves and reproductive leaves were collected for morphometric analysis.

In the second study, a total of 9 populations were randomly selected at nine sites located along an altitudinal transect from 980 to $2100 \mathrm{~m}$ at the Jinfo Mountain Nature Reserve in 2012 of July and August. From each population, ten complete vegetative leaves and reproductive leaves were collected for morphometric analysis. The leaf traits were measured by Image-Pro Plus6.0 software. The leaf length was the length from the tip to the end of the leaf, and the width was the width at the widest point of the leaf. The area of a single leaf is the area of the whole leaf; FAA $=2 \times|\mathrm{RA}-\mathrm{LA}| /(\mathrm{RA}+\mathrm{LA}), \mathrm{RA}$ is the abbreviation of Right Leaf Area, LA is the abbreviation of Left Leaf Area; FAW $=2 \times|\mathrm{RW}-\mathrm{LW}| /(\mathrm{RW}+$ LW), RW is the abbreviation of Right Leaf Width, LW is the abbreviation of Left Leaf Width. The plant traits and their definitions in this work were listed in Tab. 2 [27].

Table 2: Plant functional traits and abbreviations used in this article, together with definitions

\begin{tabular}{lll}
\hline Plant functional trait & Abbreviation & Definition \\
\hline Fluctuating asymmetry of leaf area & FAA & $2 *|\mathrm{RA}-\mathrm{LA}| /(\mathrm{RA}+\mathrm{LA})$ \\
Fluctuating asymmetry of leaf width & FAW & $2 * \mid \mathrm{RW}-\mathrm{LW} / / \mathrm{RW}+\mathrm{LW})$ \\
Root to shoot ratio & R/S Ratio & Root dry mass/shoot dry mass \\
Coefficient of variation & CV & Standard deviation/average \\
\hline
\end{tabular}

\subsection{Statistical Analysis}

We used two-way ANOVAs to test effects of region (east $v s$. center $v s$. west) and leaf type (vegetative $v s$. reproductive leaf), and effects of elevation $(980,1086,1270,1350,1480,1600,1800,1920,2100 \mathrm{~m})$ and leaf type on leaf traits (e.g., leaf length, leaf width, length/width of leaf and leaf area), coefficient of variation $(\mathrm{CV})$ of the leaf traits and fluctuating asymmetry of leaf area and of leaf width (FAA and FAW). If significant effects were detected, then multiple post-hoc Tukey's HSD tests were used to compare the means of the treatments. We also used one-way ANOVAs to test effects of regions on the number of ramets and R/S Ratio. If a significant effect of regions was detected, then Tukey tests was conducted to compare the means among the treatments. Differences were considered significant at $P<0.05$ level. Data were square root transformed prior to statistical analysis to meet the assumptions of normality. SPSS statistical package was used for all analyses (SPSS 11 Copyright: SPSS Inc.). Figures were drawn by Origin Pro 7.0 (Software). 


\section{Results}

\subsection{Number of Ramets and R/S Ratio of E. annuus in Response to the Region}

The region had a significant effect on number of ramets of $E$. annuus $(P<0.001)$ (Tab. 3). Eastern region accumulated greater number of ramets than central and western regions. However, to some extent, there was an opposite trend in $\mathrm{R} / \mathrm{S}$ ratio $(P=0.059)$.

Table 3: General features of morphology and biomass allocation of Erigeron annuus in different regions in China. Significance levels

\begin{tabular}{llllll}
\hline & \multicolumn{4}{c}{ Region } & \\
\cline { 2 - 5 } & East & Center & West & $F$ & $P$ \\
\hline No. of ramets per plant & $5.54 \pm 0.65^{\mathrm{a}}$ & $1.55 \pm 0.18^{\mathrm{b}}$ & $1.20 \pm 0.11^{\mathrm{b}}$ & $\mathbf{2 4 . 2 9 3}$ & $<\mathbf{0 . 0 0 1 * * *}$ \\
R/S ratio & $0.10 \pm 0.007^{\mathrm{a}}$ & $0.13 \pm 0.010^{\mathrm{a}}$ & $0.13 \pm 0.009^{\mathrm{a}}$ & 2.904 & 0.059 \\
\hline
\end{tabular}

Note: $F$ values and the significance levels $(* * * P<0.001, * * P<0.01, * P<0.05)$ are showed, different letters indicate statistically significant comparisons.

\subsection{Leaf Traits in Response to the Region and Leaf Type}

Leaf type had a significant effect on the leaf traits (e.g., leaf length, leaf width, length/width of leaf and leaf area) of $E$. annuus $(P<0.001)$. Vegetative leaves tended to be larger and longer (leaf length, leaf width and leaf area) than reproductive leaves (Tab. 4, Fig. 2).

Table 4: ANOVA results of effects of region (east $v s$. center $v s$. west), leaf type (vegetative $v s$. reproductive leaf) and their interactions on plant functional traits Erigeron annuus in China

\begin{tabular}{|c|c|c|c|c|c|c|}
\hline & \multicolumn{2}{|c|}{ Region (R) } & \multicolumn{2}{|c|}{ Leaf type (L) } & \multicolumn{2}{|l|}{$\mathrm{R} \times \mathrm{L}$} \\
\hline & $F$ & $P$ & $F$ & $P$ & $F$ & $P$ \\
\hline Leaf length & 14.692 & $<0.001 * * *$ & 376.397 & $<0.001 * * *$ & 9.973 & $<0.001 * * *$ \\
\hline Leaf width & 2.256 & 0.107 & 398.420 & $<0.001 * * *$ & 4.098 & $0.018 *$ \\
\hline Length/width of leaf & 0.230 & 0.795 & 134.633 & $<0.001 * * *$ & 3.006 & 0.052 \\
\hline Leaf area & 3.837 & $0.023 *$ & 339.876 & $<0.001 * * *$ & 4.263 & $0.015^{*}$ \\
\hline $\mathrm{CV}$ of leaf length & 4.075 & $0.025^{*}$ & 1.397 & 0.245 & 0.204 & 0.816 \\
\hline CV of leaf width & 4.484 & $0.018^{*}$ & 0.043 & 0.837 & 0.427 & 0.656 \\
\hline $\mathrm{CV}$ of length/width & 0.413 & 0.665 & 2.657 & 0.112 & 0.415 & 0.664 \\
\hline CV of leaf area & 11.455 & $<0.001 * * *$ & 2.721 & 0.108 & 0.045 & 0.956 \\
\hline FAW & 79.793 & $<0.001 * * *$ & 0.042 & 0.838 & 0.679 & 0.507 \\
\hline FAA & 80.922 & $<0.001 * * *$ & 0.367 & 0.545 & 3.029 & 0.049* \\
\hline
\end{tabular}

Note: $F$ values and the significance levels $\left({ }^{* * *} P<0.001,{ }^{* *} P<0.01, * P<0.05\right)$ are showed.

In addition, the effects of east-center-west regions on leaf length, leaf area, CV of leaf length, leaf width and leaf area, FAW and FAA were significant (Tab. 4). CV of leaf length was significantly higher in center region, CV of leaf area was significantly higher in west region, and CV of leaf width and FAW were significantly higher in center and west region than those in east region (Tab. 4, Fig. 2). Leaf length, width, leaf area and FAA, showed the greater difference between vegetative and reproductive leaf in 
central region than in other two regions (significant region $\times$ leaf type interactions in Tab. 4, Fig. 2). FAA was significantly greater in vegetative leaf than reproductive leaf in center region, whereas there was no significance in other two regions.

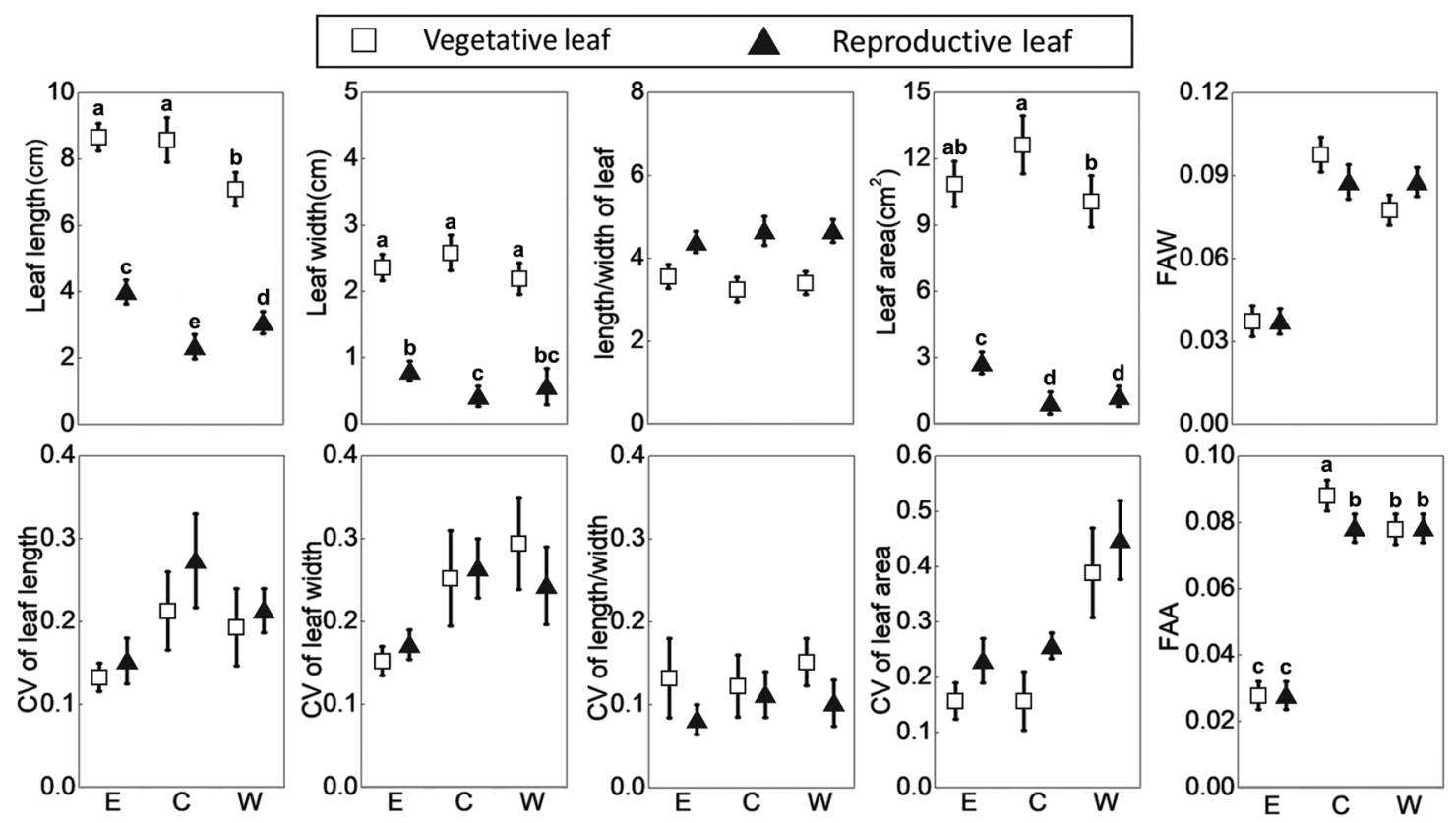

Figure 2: Effects of region (east vs. center vs. west, E represent east region, C represent center region, W represent west region), leaf type (vegetative $v s$. reproductive leaf) on the leaf traits (e.g., leaf length, leaf width, length/width of leaf and leaf area), CV of the leaf traits and FA (FAA and FAW) of Erigeron annuus in China. Means $+1 \mathrm{SE}$ are showed, different letters indicate statistically significant comparisons

\subsection{Leaf Traits in Response to the Elevation and Leaf Type in the West Region}

$\mathrm{CV}$ of all leaf traits were not significantly affected by elevation and leaf type (Tab. 5). Although the main effects of elevation and leaf type were significant for leaf length, leaf width, length/width of leaf, leaf area, FAW and FAA, elevation $\times$ leaf type interactions was significance for leaf adaptation in west region (Tab. 5). In the elevations of 980,1086 and $1350 \mathrm{~m}$, leaf length, leaf width, and leaf area of vegetative leaves were significantly greater than reproductive leaf in comparison to other elevations (significant elevation $\times$ leaf type interactions in Tab. 5, Fig. 3).

FAA and FAW of reproductive leaves in the elevation of $1270 \mathrm{~m}$ had a significant rise, which indicated the high significant difference in FAA and FAW in $1270 \mathrm{~m}$ between vegetative and reproductive leaf, whereas there was no significance between leaf type in other elevations (significant elevation $\times$ leaf type interactions in Tab. 5, Fig. 3).

\section{Discussion}

The significant influence of region indicated that leaf length and leaf area were significantly higher in eastern region than in central and western ones. To some extent, ramets of E. annuus decreased significantly with from east to west. The CV of leaf traits and FA in eastern region were lower than those in central and western ones. Besides, the interaction between region and leaf type was significant for all leaf traits. These results suggest that region is very important for E. annuus in growth and leaf adaptation. Also, region had different effects on vegetative leaves and reproductive leaves. 
Table 5: ANOVA results of effects of elevation (980, 1086, 1270, 1350, 1480, 1600, 1800, 1920, $2100 \mathrm{~m}$ ), leaf type (vegetative $v s$. reproductive leaf) and their interactions on plant functional traits of Erigeron annuus in West region

\begin{tabular}{|c|c|c|c|c|c|c|}
\hline & \multicolumn{2}{|c|}{ Elevation (E) } & \multicolumn{2}{|c|}{ Leaf type (L) } & \multicolumn{2}{|c|}{$\mathrm{E} \times \mathrm{L}$} \\
\hline & $F$ & $P$ & $F$ & $P$ & $F$ & $P$ \\
\hline Leaf length & 22.527 & $<0.001 * * *$ & 922.766 & $<0.001 * * *$ & 18.635 & $<0.001 * * *$ \\
\hline Leaf width & 16.672 & $<0.001 * * *$ & 464.660 & $<0.001 * * *$ & 14.171 & $<0.001 * * *$ \\
\hline Length/Width of leaf & 8.606 & $<0.001 * * *$ & 157.770 & $<0.001 * * *$ & 3.100 & $0.002 * *$ \\
\hline Leaf area & 20.423 & $<0.001 * * *$ & 436.230 & $<0.001 * * *$ & 18.264 & $<0.001 * * *$ \\
\hline $\mathrm{CV}$ of leaf length & 0.921 & 0.511 & 0.856 & 0.361 & 0.936 & 0.499 \\
\hline CV of leaf width & 1.648 & 0.146 & 3.188 & 0.083 & 2.052 & 0.068 \\
\hline CV of length/Width & 1.950 & 0.082 & 1.366 & 0.250 & 1.429 & 0.218 \\
\hline CV of leaf area & 0.907 & 0.522 & 0.007 & 0.936 & 0.927 & 0.506 \\
\hline FAW & 11.963 & $<0.001 * * *$ & 7.633 & $0.006 * *$ & 18.756 & $<0.001 * * *$ \\
\hline FAA & 45.099 & $<0.001 * * *$ & 50.317 & $<0.001 * * *$ & 51.017 & $<0.001 * * *$ \\
\hline
\end{tabular}

Note: $F$ values and the significance levels $\left({ }^{* * *} P<0.001,{ }^{* *} P<0.01,{ }^{*} P<0.05\right)$ are showed.

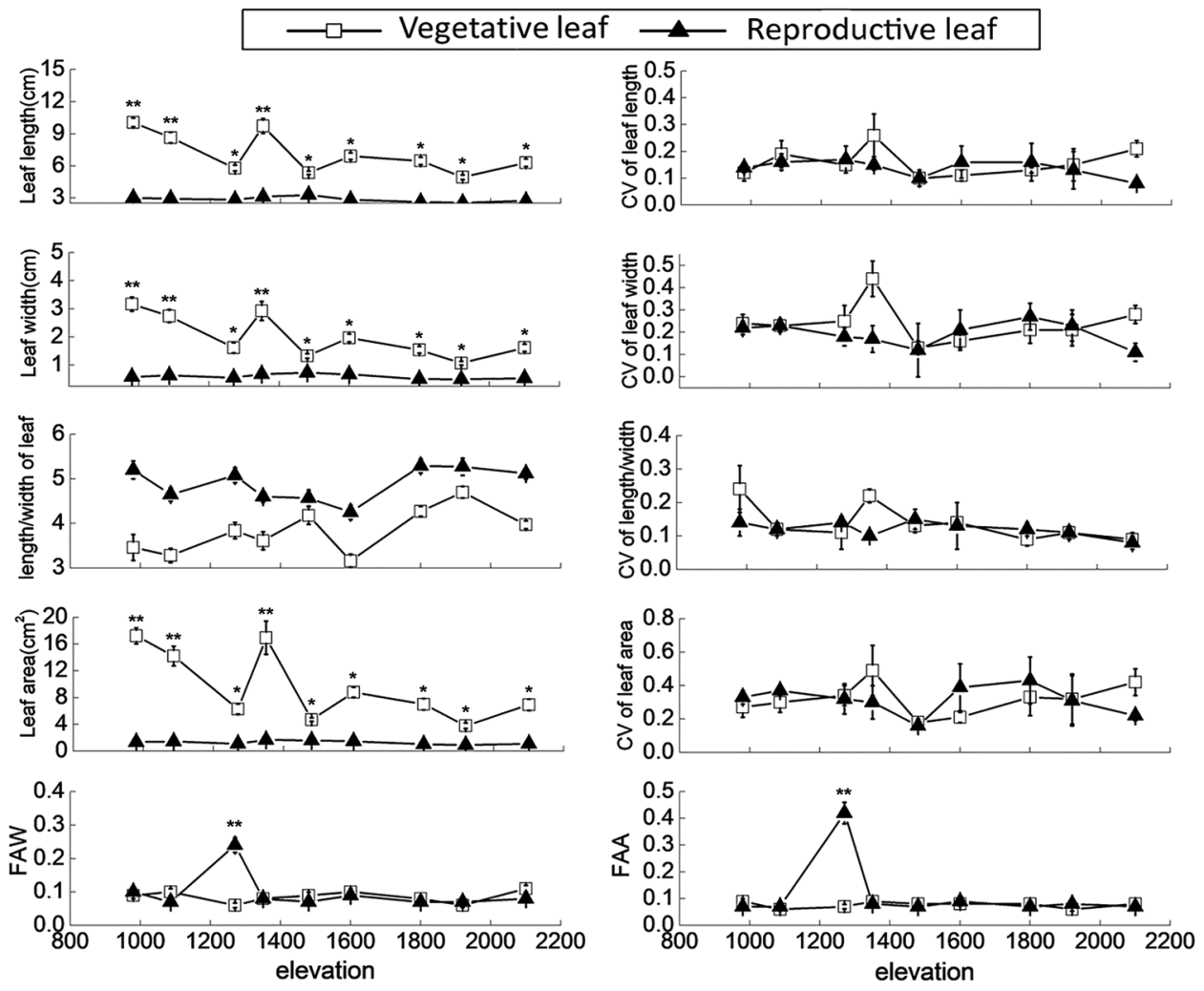

Figure 3: Effects of elevation (980, 1086, 1270, 1350, 1480, 1600, 1800, 1920, $2100 \mathrm{~m}$ ), leaf type (vegetative $v s$. reproductive leaf) on the leaf traits (e.g., leaf length, leaf width, length/width of leaf and leaf area), CV of the leaf traits and FA (FAA and FAW) of Erigeron annuus in west region. Means + $1 \mathrm{SE}$ are showed, significant effects are indicated as follows: $* * * P<0.001, * * P<0.01, * P<0.05$ 
The results indicated that the adaptive of E. annuus in eastern site was stronger than the central and western site, in another words, it meant that the former invasive plants grow better than the latter. Size and shape of leaves depend on a variety of factors, including phylogeny, developmental constraints and physiological and biomechanical demands imposed by habitat conditions such as light regimen, temperature, humidity, soil $\mathrm{pH}$ and nutrient and water availability [49]. In our study, water may be one main reason to explain that leaf length, and leaf area were significantly more lager in eastern site than in central and western ones. Water availability is particularly variable, because the east region receives more rain than the west and central regions. Variation in leaf length, leaf width and leaf area according to water availability is a common morphophysiological adjustment in plants, that can involve plasticity, genetic differentiation or both [50-53]. In addition, adaptation period is another factor considered for plant growth in many terrestrial ecosystems. E. annuus was first brought to eastern site, then through above 50 years of stagnation, gradually spread from eastern coastal to the western inland [54-57]. So, compared with central and western site, alien invasive species of $E$. annuus have more time to adapt new environment in eastern site. It may result that the ability of absorption of nitrogen and phosphorus in eastern site will be stronger than in central and western site. Moreover, it is necessary to consider for differences in genetic factor in studies of E. annuus. Genetic diversity can be reduced topically by founder effects with long distance dispersal and rapid redistribution of genetic diversity might result in experiencing high gene flow [58,59]. It may also mean that an efficient maintenance of diversity across the newly central and western region by reducing drift compared to the eastern region. That's may be another reason for the former invasive plants grow better than the latter.

$\mathrm{CV}$ and FA are supposed to be a sensitive estimator of stresses from environment and fitness of species [60]. The CV of leaf traits and FA in eastern region were lower than those in central and western ones. We have known that there are almost no differences in environment for three regions except precipitation of rainfall [51,52]. It suggested that the fitness of E. annuus in eastern site was stronger than the central and western site. Favorable environments allowed a faster growth of plants, but not prompting lower developmental instability and FA levels [61]. Therefore, the adaptation time may be the main reason for the CV of leaf traits and FA in eastern region was lower than others.

The significant influence of elevation indicated that the all leaf traits of $E$. annuus could be affected in Jinfo Mountain. What's more, in the elevation of $1300 \mathrm{~m}$, the all leaf traits of reproductive leaves were higher than others. Leaf of CV and FA as well as leaf phenology exhibited a clear linear relationship with elevation. In addition, the interaction between region and leaf type was significant for all leaf traits. These results suggest that appropriate elevation is very important for $E$. annuus to grow better. Thus, our results partly reinforce the first hypotheses, suggesting that higher adaptive levels should occur in Jinfo Mountain along 9 transects.

The results indicated that the adaptive of $E$. annuus in elevation of $1300 \mathrm{~m}$ was higher than the others. Nitrogen and phosphorus are the two primary limiting resources for plant growth $[62,63]$. Therefore, an increment in nutrient availability may modify organ/module production such as leaves, ramets, roots and inflorescences [64], which in turn affects these differences as a result of uptake and use efficiency of nutrients by plants. As mentioned above, plants growth might be affected by habitat conditions such as light regimen, temperature, humidity and nutrient and water availability. In this case, temperature might be the major factor that causes the stress level of the plants to increase. Compared with other factors, temperature decreased significantly with increasing elevation. According to intermediate disturbance hypothesis, invasive plants should be adapted to moderate elevation of mountain regions, higher or lower temperature; it is not fit for plant growth [25]. So, we can preliminary infer that species of E. annuus grow better in the elevation of $1300 \mathrm{~m}$. This result is consistent with previous findings that abiotic forces have likely been important in the evolution of plant function on contrasting ends of elevation gradients $[65,66]$. 
Besides, we found that $\mathrm{CV}$ and FA are significantly greater in leaves of E. annuus that occur in elevation of $1300 \mathrm{~m}$ compared with others. In fact, in some cases we should consider the more favorable conditions about higher CV and FA, like higher nutrient availability [67], less polluted soil [68], or water supplementation [69]. In this study, we found that favorable environments allow a faster growth of plants, prompting higher developmental instability and FA levels [70-72]. Also, leaf size could be increased by $\mathrm{CV}$ and FA because larger leaves require more resources to be produced [62].

\section{Conclusions}

This observational study, carrying out a detailed analysis of how leaf phenotype of E. annuus responds to regions and gradual increases in elevation. Indeed, leaf morphology and size differ between the three regions from east to west, with larger leaves, higher developmental stability and FA levels in eastern site than the central and western site. Higher CV and FA levels occur in elevation of $1300 \mathrm{~m}$, meanwhile, it is favorable micro-environmental conditions for plant development. Our results illustrate the complexities associated with understanding the relationship among FA and environmental stress and highlight the necessity of future studies that provides some insights into understanding the differences between exotic species and native species. It can also facilitate the understanding of the invasiveness in the agroecosystems in China.

Acknowledgement: We thank Yongjian Wang and Qiang Fu designed the experiment, Zhen Li and Qiang Fu performed the experiment, Yongjian Wang, and Yuanyuan Liu did the statistical analysis, Yuanyuan Liu, Zhen $\mathrm{Li}$ and Lie $\mathrm{Xu}$ wrote the first draft of the manuscript, Yongjian Wang and Qiang Fu contributed substantially to the revisions and thank Xiaohui Yong and Jianghua Liu for their assistance in the field work.

Funding Statement: This study was supported by the National Natural Science Foundation of China (Nos. 31770449, 31270465) and Fundamental Research Funds for the Central Universities (2662020YLPY016, 2662016PY064).

Conflicts of Interest: The authors declare that they have no conflicts of interest to report regarding the present study.

\section{References}

1. Capinha, C., Essl, F., Seebens, H., Moser, D., Pereira, H. M. (2015). The dispersal of alien species redefines biogeography in the anthropocene. Science, 348, 1248-1251. DOI 10.1126/science.aaa8913.

2. Case, T., Holt, R. M., McPeek, M. A., Keitt, T. (2005). The community context of species' borders: Ecological and evolutionary perspectives. Oikos, 108, 28-46. DOI 10.1111/j.0030-1299.2005.13148.x.

3. Lenzner, B., Magallón, S., Dawson, W., Kreft, H., König, C. et al. (2020). Role of diversification rates and evolutionary history as a driver of plant naturalization success. New Phytologist, 229, 2998-3008. DOI 10.1111/nph.17014.

4. Early, R., Keith, S. A. (2019). Geographically variable biotic interactions and implications for species ranges. Global Ecology and Biogeography, 28, 42-53. DOI 10.1111/geb.12861.

5. Keane, R. M., Crawley, M. J. (2002). Exotic plant invasions and the enemy release hypothesis. Trends in Ecology \& Evolution, 17, 164-170. DOI 10.1016/S0169-5347(02)02499-0.

6. Lehmann, P., Ammunét, T., Barton, M., Battisti, A., Eigenbrode, S. D. et al. (2020). Complex responses of global insect pests to climate warming. Frontiers in Ecology Environment, 18, 141-150. DOI 10.1002/fee.2160.

7. Oduor, A. M. O., van Kleunen, M., Stift, M. (2020). Allelopathic effects of native and invasive brassica nigra do not support the novel-weapons hypothesis. American Journal of Botany, 107, 1106-1113. DOI 10.1002/ajb2.1516.

8. Fratte, D., Bolpagni, M., Brusa, R., Caccianiga, G., Pierce, M. et al. (2019). Alien plant species invade by occupying similar functional spaces to native species. Flora, 257, 151419. DOI 10.1016/j.flora.2019.151419. 
9. Guo, W. Y., van Kleunen, M., Winter, M., Weigelt, P., Stein, A. et al. (2018). The role of adaptive strategies in plant naturalization. Ecology Letters, 21, 1380-1389. DOI 10.1111/ele.13104.

10. Liu, Y. Y., Sun, Y., Müller-Schärer, H., Yan, R., Zhou, Z. X. et al. (2019). Do invasive alien plants differ from noninvasives in dominance and nitrogen uptake in response to variation of abiotic and biotic environments under global anthropogenic change? Science of the Total Environment, 672, 634-642. DOI 10.1016/j. scitotenv.2019.04.024.

11. Wang, Y. J., Chen, D., Yan, R., Yu, F. H., van Kleunen, M. (2019). Invasive alien clonal plants are competitively superior over co-occurring native clonal plants. Perspectives in Plant Ecology, Evolution and Systematics, 40, 125484. DOI 10.1016/j.ppees.2019.125484.

12. Zhao, C. Y., Liu, Y. Y., Shi, X. P., Wang, Y. J. (2020). Effects of soil nutrient variability and competitor identify on growth and co-existence among invasive alien and native clonal plants. Environmental Pollution, 261, 113894. DOI 10.1016/j.envpol.2019.113894.

13. Essl, F., Lenzner, B., Bacher, S., Bailey, S., Capinha, C. et al. (2020). Drivers of future alien species impacts: An expert-based assessment. Global Change Biology, 26, 4880-4893. DOI 10.1111/gcb.15199.

14. Mitchell, C. E., Agrawal, A. A., Bever, J. D., Gilbert, G. S., Hufbauer, R. A. et al. (2006). Biotic interactions and plant invasions. Ecology Letters, 9, 726-740. DOI 10.1111/j.1461-0248.2006.00908.x.

15. Qiu, S. Y., Liu, S. S., Wei, S. J., Cui, X. H., Nie, M. et al. (2020). Changes in multiple environmental factors additively enhance the dominance of an exotic plant with a novel trade-off pattern. Journal of Ecology, 8, 1989-1999. DOI 10.1111/1365-2745.13386.

16. Chen, D., Ali, A., Yong, X. H., Lin, C. G., Niu, X. H. et al. (2019a). A multi-species comparison of selective placement patterns of ramets in invasive alien and native clonal plants to light, soil nutrient and water heterogeneity. Science of the Total Environment, 657, 1568-1577. DOI 10.1016/j.scitotenv.2018.12.099.

17. Chen, D., Xiong, H., Lin, C. G., He, W., Zhang, Z. W. et al. (2019b). Clonal integration benefits invasive alien plants under water variability in a native community. Journal of Plant Ecology, 12, 574-582. DOI 10.1093/jpe/rty050.

18. Daehler, C. C. (2003). Performance comparisons of co-occurring native and alien invasive plants: Implications for conservation and restoration. Annual Review of Ecology Evolution \& Systematics, 34, 183-211. DOI 10.1146/ annurev.ecolsys.34.011802.132403.

19. Davis, M. A., Pelsor, M. (2001). Experimental support for a resource-based mechanistic model of invasibility. Ecology Letters, 4, 421-428. DOI 10.1046/j.1461-0248.2001.00246.x.

20. Liu, Y. J., van Kleunen, M. (2017). Responses of common and rare aliens and natives to nutrient availability and fluctuations. Journal of Ecology, 105, 1111-1122. DOI 10.1111/1365-2745.12733.

21. Chytrý, M., Maskell, L. C., Pino, J., Pyšek, P. (2008). Habitat invasions by alien plants: A quantitative comparison among Mediterranean, subcontinental and oceanic regions of Europe. Journal of Applied Ecology, 45, 448-458. DOI 10.1111/j.1365-2664.2007.01398.x.

22. Wang, Y. J., Müller-Schärer, H., van Kleunen, M., Cai, A. M., Zhang, P. et al. (2017). Invasive alien plants benefit more from clonal integration in heterogeneous environments than natives. New Phytologist, 216, 1072-1078. DOI 10.1111/nph.14820.

23. Becker, T., Dietz, H., Billeter, R., Buschmann, H., Edwards, P. J. (2005). Altitudinal distribution of alien plant species in the swiss alps. Perspectives in Plant Ecology Evolution \& Systematics, 7, 173-183. DOI 10.1016/j. ppees.2005.09.006.

24. Rabitsch, W., Essl, F. (2006). Biological invasions in Austria: Patterns and case studies. Biological Invasions, 8, 295-308. DOI 10.1007/s10530-004-7890-3.

25. Osman, R. W. (2015). The intermediate disturbance hypothesis. Encyclopedia of Ecology (Second Edition), vol. 3, pp. 441-450. DOI 10.1016/B978-0-12-409548-9.09480-X.

26. Pauchard, A., Alaback, P. B. (2004). Influence of elevation, land use, and landscape context on patterns of alien plant invasions along roadsides in protected areas of south-central Chile. Conservation Biology, 18, 238-248. DOI 10.1111/j.1523-1739.2004.00300.x. 
27. Liu, J. H., Yong, X. H., Han, Q., Ali, A., Wang, Y. J. (2017). Response of plant functional traits to species origin and adaptive reproduction in weeds. Plant Biosystems, 151, 323-330. DOI 10.1080/11263504.2016.1174171.

28. Landia, M., Zivcak, M., Sytar, O., Brestic, M., Allakhverdie, S. I. (2019). Plasticity of photosynthetic processes and the accumulation of secondary metabolites in plants in response to monochromatic light environments: A review. Biochimica et Biophysica Acta (BBA)-Bioenergetics, 1861, 148131. DOI 10.1016/j.bbabio.2019.148131.

29. Sultan, S. E. (2000). Phenotypic plasticity for plant development, function and life history. Trends in Plant Science, 5, 537-542. DOI 10.1016/S1360-1385(00)01797-0.

30. Rosas, T., Mencuccini, M., Barba, J., Cochard, H., Saura-Mas, S. et al. (2019). Adjustments and coordination of hydraulic, leaf and stem traits along a water availability gradient. New Phytologist, 223, 632-646. DOI 10.1111/ nph.15684.

31. Miner, B. G., Sultan, S. E., Morgan, S. G., Padilla, D. K., Relyea, R. A. (2005). Ecological consequences of phenotypic plasticity: Trends in ecology \& evolution. Trends in Ecology \& Evolution, 20, 685-692. DOI 10.1016/j.tree.2005.08.002.

32. Pigliucci, M. (2001). Phenotypic plasticity: Beyond nature and nurture. Genomics, 304, 397-399.

33. Wei, N., Cronn, R., Liston, A., Ashman, T. L. (2019). Functional trait divergence and trait plasticity confer polyploid advantage in heterogeneous environments. New Phytologist, 221, 2286-2297. DOI 10.1111/nph.15508.

34. Sultan, S. E. (2004). Promising directions in plant phenotypic plasticity. Perspectives in Plant Ecology, 6, $227-$ 233. DOI 10.1078/1433-8319-00082.

35. Sultan, S. E. (1995). Phenotypic plasticity and plant adaptation. Acta Botanica Neerlandica, 44, 363-383. DOI 10.1111/j.1438-8677.1995.tb00793.x.

36. Moller, A. P. (1997). Developmental stability and fitness: A review. American Naturalist, 149, 916-932. DOI $10.1086 / 286030$.

37. Lv, W. J., Guo, S. J., Li, G. H., Xiong, H. (2012). Correlation between nutrition materials in leaves of bearing shoot during pollination and fertilization of chestnut. Acta Agriculturae Universitatis Jiangxiensis, 34, 960-964. DOI 10.13836/j.jjau.2012175.

38. Palmer, A. R. (1996). Waltzing with asymmetry. Bioscience, 46, 518-532. DOI 10.2307/1312930.

39. Palmer, A. R., Strobeck, C. (1986). Fluctuating asymmetry: Measurement, analysis, patterns. Annual Review of Ecology \& Systematics, 17, 391-421. DOI 10.1146/annurev.es.17.110186.002135.

40. Leamy, L. J., Klingenberg, C. P. (2005). The genetics and evolution of fluctuating asymmetry. Annual Review of Ecology Evolution \& Systematics, 14, 1-21. DOI 10.1146/annurev.ecolsys.36.102003.152640.

41. Moller, A. P. (1996). Parasitism and developmental instability of hosts: A review. Oikos, 77, 189-196. DOI $10.2307 / 3546057$.

42. Rettig, J., Fuller, R., Corbett, A. T. (1997). Fluctuating asymmetry indicates levels of competition in an even-aged poplar clone. Oikos, 80, 123-127. DOI 10.2307/3546523.

43. Wilsey, B. J., Haukioja, E., Koricheva, J., Sulkioja, A. J. (1998). Leaf fluctuating asymmetry increases with hybridization and elevation in tree-line birches. Ecology, 79, 2092-2099. DOI 10.1890/0012-9658(1998)079 [2092:LFAIWH]2.0.CO;2.

44. Zvereva, E. L., Haukioja, E. (1997). Stress responses of salix Borealis to pollution and defoliation. Journal of Applied Ecology, 34, 1387-1396. DOI 10.2307/2405256.

45. Edwards, P. J., Baltisberger, M. (2006). Genetic variation in native and invasive populations of Erigeron annuus as assessed by RAPD markers. International Journal of Plant Sciences, 167, 93-101. DOI 10.1086/498729.

46. Stratton, D. A. (1992). Life-cycle components of selection in Erigeron annuus. I. Phenotypic selection. Evolution, 46, 92-106. DOI 10.2307/2409807.

47. Bruelheide, H., Heinemeyer, A. (2002). Climatic factors controlling the eastern and altitudinal distribution boundary of Digitalis purpurea L. in Germany. Flora, 197, 475-490. DOI 10.1078/0367-2530-00064.

48. Trtikova, M., Edwards, P. J., Gtisewell, S. (2010). No adaptation to altitude in the invasive plant Erigeron annuus in the swiss alps. Ecography, 33, 556-564. DOI 10.1111/j.1600-0587.2009.05708.x. 
49. Trtikova, M., Giisewell, S., Baltisberger, M., Edwards, P. J. (2011). Distribution, growth performance and genetic variation of Erigeron annuиs in the swiss alps. Biological Invasions, 13, 413-422. DOI 10.1007/ s10530-010-9835-3.

50. Wang, R., Wang, Y. Z., Wan, F. H. (2010). Spatiotemporal expansion pattern and potential spread of invasive alien plant Erigeron annuus (Asteraceae) in China. Chinese Journal of Ecology, 29, 1068-1074. DOI 10.13292/j.10004890.2010 .0165

51. http://data.cma.cn. Database.

52. Yi, S. R., Huang, Y. (2004). Preliminary floristic study on seed plants from jinfo mountain. Acta Botanica BorealiOccidentalia Sinica, 24, 83-93.

53. Lott, E. J., Solis-Magallanes, J. A. (1987). Floristic diversity and structure of upland and arroyo forests of coastal jalisco. Biotropica, 19, 228-235. DOI 10.2307/2388340.

54. Calagari, M., Modirrahmati, A. R., Asadi, F. (2006). Morphological variation in leaf traits of Populus euphratica oliv. natural populations. International Journal of Agriculture \& Biology, 8, 754-758.

55. Jonas, C. S., Geber, M. A. (1999). Variation among populations of Clarkia unguiculata (Onagraceae) along altitudinal and latitudinal gradients. American Journal of Botany, 86, 333-343. DOI 10.2307/2656755.

56. Li, C. Y., Zhang, X. J., Liu, X. L., Luukkanen, O., Berninger, F. (2006). Leaf morphological and physiological responses of Quercus aquifolioides along an altitudinal gradient. Silva Fennica, 40, 5-13. DOI 10.14214/sf.348.

57. Royer, D., Wilf, P., Janesko, D., Kowalski, E., Dilcher, D. (2005). Correlations of climate and plant ecology to leaf size and shape: Potential proxies for the fossil record. American Journal of Botany, 92, 1141-1151. DOI 10.3732/ ajb.92.7.1141.

58. Bialozyt, R., Ziegenhagen, B., Petit, R. J. (2006). Contrasting effects of long distance seed dispersal on genetic diversity during range expansion. Journal of Evolutionary Biology, 19, 12-20. DOI 10.1111/j.14209101.2005.00995.x.

59. Davies, S., White, A., Lowe, A. (2004). An investigation into effects of long-distance seed dispersal on organelle population genetic structure and colonization rate: A model analysis. Heredity, 93, 566-576. DOI 10.1038/sj. hdy.6800555.

60. Lens, L., Dongen, S. V., Matthysen, E. (2002). Fluctuating asymmetry as an early warning system in the critically endangered taita thrush. Conservation Biology, 16, 479-487. DOI 10.1046/j.1523-1739.2002.00516.x.

61. Pablo, C. R., Ken, O., Antonio, G. R. G., Wilson, F., Luis, M. C. (2011). Contrasting herbivory patterns and leaf fluctuating asymmetry in heliocarpus pallidus between different habitat types within a Mexican tropical dry forest. Journal of Tropical Ecology, 27, 383-391. DOI 10.1017/S026646741100006X.

62. Bobbink, R., Hicks, K., Galloway, J., Spranger, T., Alkemade, R. et al. (2010). Global assessment of nitrogen deposition effects on terrestrial plant diversity: A synthesis. Ecological Applications, 20, 30-59. DOI 10.1890/08-1140.1.

63. Perring, M. P., Hedin, L. O., Levin, S. A., Mcgroddy, M., de Mazancourtet, C. (2008). Increased plant growth from nitrogen addition should conserve phosphorus in terrestrial ecosystems. Proceedings of the National Academy of Sciences, 105(6), 1971-1976. DOI 10.1073/pnas.0711618105.

64. Aerts, R., Lii, F. S. C. (1999). The mineral nutrition of wild plants revisited: A-evaluation of processes and patterns. Advances in Ecological Research, 30, 1-67. DOI 10.1016/S0065-2504(08)60016-1.

65. Stevens, R. D., Willig, M. R., Strauss, R. E. (2006). Latitudinal gradients in the phenetic diversity of New world bat communities. Oikos, 112, 41-50. DOI 10.1111/j.0030-1299.2006.13167.x.

66. Swenson, N., Enquist, B. J., Pither, J., Kerkhoff, A. J., Boyle, B. et al. (2012). The biogeography and filtering of woody plant functional diversity in north and South America. Global Ecology \& Biogeography, 21, 798-808. DOI 10.1111/j.1466-8238.2011.00727.x.

67. Milligan, J. R., Krebs, R. A. (2008). Separating developmental and environmental effects on fluctuating asymmetry in Lythrum salicaria and Penthorum sedoides. International Journal of Plant Sciences, 169, 625630. DOI 10.1086/533600.

68. Velickovic, M., Perisic, S. (2006). Leaf fluctuating asymmetry of common plantain as an indicator of habitat quality. Plant Biosystems, 140, 138-145. DOI 10.1080/11263500600756322. 
69. Fair, J. M., Breshears, D. D. (2005). Drought stress and fluctuating asymmetry in quercus undulata leaves: Confounding effects of absolute and relative amounts of stress. Journal of Arid Environments, 62, 235-249. DOI 10.1016/j.jaridenv.2004.11.010.

70. Hochwender, C., Fritz, R. (1999). Fluctuating asymmetry in a salix hybrid system: The importance of genetic $v s$. environmental causes. Evolution, 53, 408-416. DOI 10.1111/j.1558-5646.1999.tb03776.x.

71. Lempa, K. J., Koricheva, J., Haukioja, E., Ossipov, V., Ossipova, S. et al. (2000). Covariation of fluctuating asymmetry, herbivory and chemistry during birch leaf expansion. Oecologia, 122, 354-360. DOI 10.1007/ s004420050041.

72. Moller, A. P., Eriksson, M. (1994). Patterns of fluctuating asymmetry in flowers: Implications for sexual selection in plants. Journal of Evolutionary Biology, 7, 97-113. DOI 10.1046/j.1420-9101.1994.7010097.x. 